\title{
A plea for avoiding systematic intubation in severely hypoxemic patients with COVID- 19-associated respiratory failure
}

\author{
Eduardo Villarreal-Fernandez ${ }^{1}$, Ravi Patel ${ }^{1}$, Reshma Golamari ${ }^{2}$, Muhammad Khalid ${ }^{2}$, Ami DeWaters ${ }^{2}$ and \\ Philippe Haouzi ${ }^{1 *}$
}

To the Editor,

In early February 2020, Yang et al. [1] reported an alarming high mortality rate in patients with COVID-19associated acute respiratory failure requiring mechanical ventilatory support. Such a dreadful outcome was regarded as the fundamental tenet dictating our strategy to treat patients with COVID-19 acute respiratory failure. Two essential recommendations were offered to the medical community in keeping with these first reports: (1) early intubation of hypoxemic patients [2]. Indeed, since a profound hypoxemia appears to be the hallmark of COVID-19-associated pneumonia, the initial consensus [2] was to start invasive mechanical ventilation as soon as possible due to the overwhelming number of patients in respiratory failure presenting at the same time in a hospital and to prevent the risk of hypoxic cardiac arrest; (2) avoidance of high-flow nasal cannula (HFNC) to reduce respiratory droplet aerosolization for healthcare workers [3] in what was seen as "inevitable" intubations.

During the very initial weeks preceding the anticipated surge in central Pennsylvania, ten patients with confirmed infection by SARS-CoV-2, who had extremely high oxygen requirement, were admitted in our institution (Harrisburg/Hershey region): all patients required a high flow of oxygen by nasal cannula $(\mathrm{NC})$ or via nonrebreather (NRB) (Fig. 1) with documented episodes of $\mathrm{SpO}_{2}<90 \%$. The first four patients underwent endotracheal intubation by day 2 of hospital admission

\footnotetext{
* Correspondence: phaouzi@pennstatehealth.psu.edu

1 Division of Pulmonary and Critical Care Medicine, Department of Medicine, Penn State Health, Pennsylvania State University, College of Medicine, 500 University Drive, Hershey, PA 17033, USA

Full list of author information is available at the end of the article
}

without a trial of high flow nasal cannula (HFNC) or non-invasive ventilation (NIV), following the recommendations for early intubation [2]. However, we reconsidered in other patients the rationale behind these early intubations and revisited the initial proposal of avoiding high flow oxygen in hypoxemic patients. In addition, we felt that the actual consequences of aerosolization posed by HFNC and NIV [4] remain quite hypothetical as reported in H1N1 pneumonia [5]. Our main concern was that a systematic intubation of every hypoxemic patient may prove to be untenable, facing a limitation of capacity and resources of intensive care units (ICU) to safely maintain a high number of patients on mechanical ventilation during the expected surge. We therefore selected a different strategy in the following six patients whose initial oxygen requirement was in the same range as the patients who were intubated by day 2 . Empiric limit of hypoxic events $\sim 88 \%$ was considered acceptable as long as the $\mathrm{SpO}_{2}$ was maintained at or above this level during most of the day and could be improved by self-prone positioning. This strategy was adopted in the absence of preexisting chronic respiratory failure, morbid obesity, concurrent clinical signs of respiratory distress, hypercapnia, alteration in hemodynamics, or lactic acidosis. We used a flow of oxygen up to $6 \mathrm{~L} / \mathrm{min} \mathrm{NC}$ and HFNC whenever higher $\mathrm{FiO}_{2}$ was needed (Fig. 1). Out of these six patients, two required invasive mechanical ventilation after failing HFNC: one patient developed respiratory fatigue and required intubation at day 3 , while the second patient had intolerance to NIV and self-prone positioning with an episode of emesis that led to intubation on day 6. The non-intubated patients were instructed to rest in a prone position as much as feasible. After an initial increase in oxygen requirement through day 6 , 


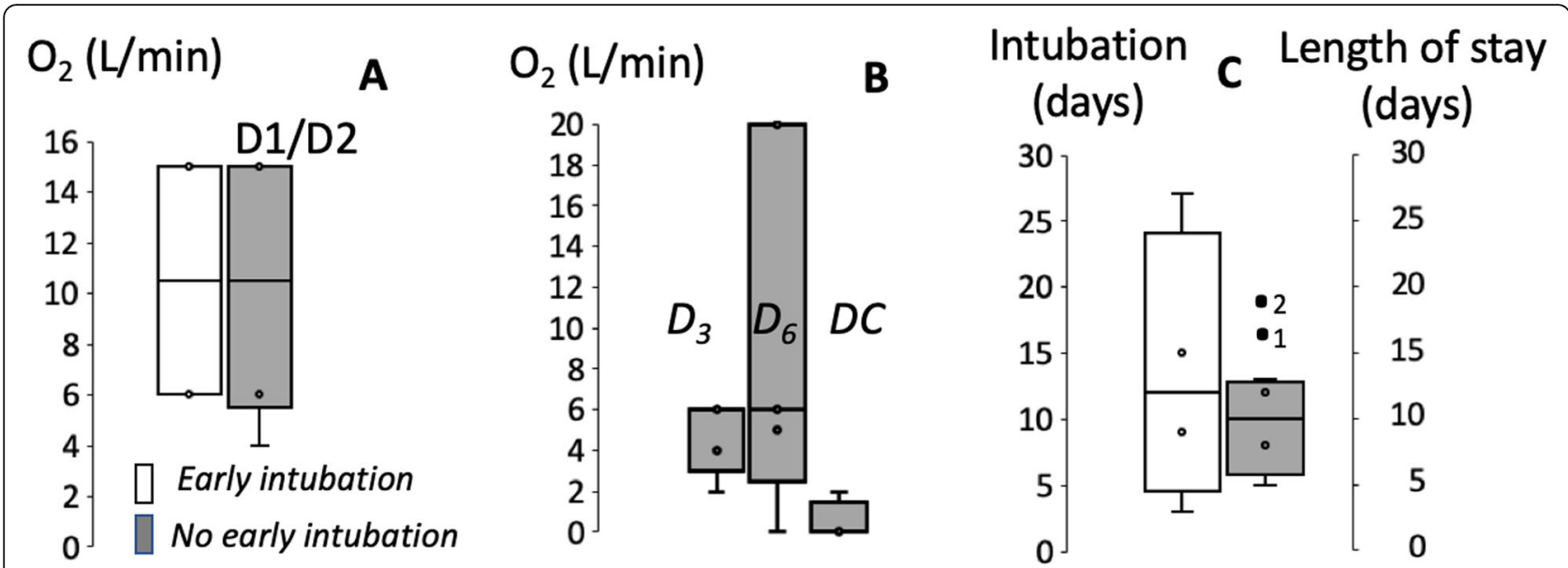

Fig. 1 a Oxygen flow requirement (median and range) during the first $48 \mathrm{~h}$ of admission in the group of patients who were intubated within the first 2 days based on the level of hypoxemia (4 patients, white bars) and those who were not immediately intubated (6 patients, grey bars). $\mathbf{b}$ Evolution of $\mathrm{O}_{2}$ requirement in patients that were not intubated initially and did not require any mechanical ventilation thereafter (4 out of 6 ). Note that $\mathrm{O}_{2}$ requirement increased over the first week in this group and required the use of HFNC in many patients. They all recovered within 12 days. c Duration of intubation in the "early-intubation" group and length of stay in the patients that were not initially intubated. The 2 patients whose intubation was delayed are displayed as (1) and (2). Patient 1 was extubated at day 16, while the second patient was still intubated at day 19 (when this report was submitted)

patients in this group were all able to be discharged at a time when most of the early-intubated patients were still mechanically ventilated (Fig. 1). Strikingly, this occurred despite similar initial oxygen requirements.

In summary, avoiding endotracheal intubation is possible in significantly hypoxemic COVID-19 patients. The rationale that led to the practice patterns suggested in earlier reports must be reevaluated, and a controlled graduated method of escalating oxygen therapy, based on individual clinical judgment, in otherwise nondistressed patients should be instituted as much as possible. Such an approach remains to be standardized.

\section{Acknowledgements}

Not applicable.

\section{Authors' contributions}

All authors read and approved the final manuscript.

\section{Funding}

No funding was required for the development of this manuscript.

\section{Availability of data and materials}

All data generated or analyzed during this study are included in this published article.

Ethics approval and consent to participate

The work did not require approval from ethics committee.

\section{Consent for publication}

No consent was required in the elaboration of this research.

\section{Competing interests}

The authors declare that they have no competing interests.

\section{Author details}

'Division of Pulmonary and Critical Care Medicine, Department of Medicine, Penn State Health, Pennsylvania State University, College of Medicine, 500
University Drive, Hershey, PA 17033, USA. ${ }^{2}$ Division of Hospital Medicine, Penn State Health, Pennsylvania State University, College of Medicine, Hershey, PA, USA.

Received: 30 May 2020 Accepted: 4 June 2020

Published online: 12 June 2020

\section{References}

1. Yang X, Yu Y, Xu J, Shu H, Xia JA, Liu H, Wu Y, Zhang L, Yu Z, Fang M, et al. Clinical course and outcomes of critically ill patients with SARS-CoV-2 pneumonia in Wuhan, China: a single-centered, retrospective, observational study. Lancet Respir Med. 2020;8(5):475-81.

2. WHO. Clinical management of severe acute respiratory infection (SARI) when COVID-19 disease is suspected. 2020. https:/www.who.int/docs/ default-source/coronaviruse/clinical-management-of-novel-cov.pdf (Accessed 17 Apr 2020).

3. Cheung JC, Ho LT, Cheng JV, Cham EYK, Lam KN. Staff safety during emergency airway management for COVID-19 in Hong Kong. Lancet Respir Med. 2020;8(4):e19.

4. Tran K, Cimon K, Severn M, Pessoa-Silva CL, Conly J. Aerosol generating procedures and risk of transmission of acute respiratory infections to healthcare workers: a systematic review. PLoS One. 2012;7(4):e35797.

5. Rello J, Pérez M, Roca O, et al. High-flow nasal therapy in adults with severe acute respiratory infection: a cohort study in patients with 2009 influenza A/ H1N1v. J Crit Care. 2012:27(5):434-9.

\section{Publisher's Note}

Springer Nature remains neutral with regard to jurisdictional claims in published maps and institutional affiliations. 